\title{
Genotypic and phenotypic characteristics associated with biofilm formation in Escherichia coli and Salmonella spp. isolated from ulam in Terengganu
}

\author{
${ }^{1}$ Bahri, A.A., ${ }^{1} *$ Wan Abdullah, W.Z., ${ }^{1}$ Lani, M.N., ${ }^{2}$ Salleh, W. and ${ }^{3}$ Alias, R. \\ ${ }^{I}$ Faculty of Fishery and Food Sciences, Universiti Malaysia Terengganu, 21030 Kuala Nerus, Terengganu, \\ Malaysia \\ ${ }^{2}$ Terengganu Food Safety and Quality Laboratory, Ministry of Health Malaysia, 21200 Kuala \\ Terengganu, Terengganu, Malaysia \\ ${ }^{3}$ Institute of Bio-IT Selangor, Universiti Selangor, Seksyen 7, 40000 Shah Alam, Selangor, Malaysia
}

\begin{abstract}
Article history:
Received: 2 July 2019

Received in revised form: 30

July 2019

Accepted: 5 August 2019

Available Online: 15 August 2019
\end{abstract}

\section{Keywords:}

Biofilm,

Colony morphology,

$\operatorname{csg} \mathrm{A}$,

Curli,

Ulam,

Kesum

\section{DOI:}

https://doi.org/10.26656/fr.2017.4(1).240

\begin{abstract}
Nowadays, the foodborne outbreaks associated with fresh produces, including ulam, are increasing worldwide. The biofilm formation or bacterial attachment to plant surface is the initial step towards the contamination in fresh produce. The biofilm phenotype of bacteria grown on congo red agar is termed as red, dry and rough (rdar) morphotype. The binding of congo red dye with both biological proteins and inert surfaces is due to the presence of curli fimbriae and cellulose as the main extracellular components. The objective of this study was to determine the rdar morphotypes, biofilm ability and the role of $\operatorname{csg} \mathrm{A}$ gene of Escherichia coli and Salmonella spp. isolated from ulam or Malaysian herbs. A total of 29 isolates, including 23 E. coli and 6 Salmonella spp. were analyzed for their ability to produce biofilm by colony morphology test, microtiter plate biofilm assay and qualitative biofilm test (pellicle formation). The presence of the $\operatorname{csg}$ A gene of E. coli was identified by PCR, which demonstrated the potential gene that able to produce curli fimbriae. Results revealed that $16(69.6 \%)$ E. coli isolates were categorized as strong biofilm producers, $2(8.7 \%)$ as moderate biofilm producers, $3(13 \%)$ as weak biofilm producers, whereas $2(8.7 \%)$ as negative biofilm producers (did not produce biofilm). While 4 (66.7\%) Salmonella spp. isolates were identified as strong biofilm producers, $1(16.7 \%)$ as moderate biofilm producers and $1(16.7 \%)$ as negative biofilm producers. Majority of the E. coli strains (69.6\%) were identified as strong biofilm producers and able to express rdar morphotypes. The ability of the of E. coli and Salmonella spp. isolates to form biofilm reveals the ability of these isolates to persist on the fresh vegetables and become hosts for the disease transmission to humans or/and animals.
\end{abstract}

\section{Introduction}

In Malaysia, a type of fresh vegetables that eaten raw or without cooking is called as ulam. Usually, people consume ulam as a side dish with rice and it acts as an appetizer. In the Southeast Asia countries, more than 120 plant species have been considered as ulam which may include leaves, shoots, seed, and fruits of vegetables (Reihani and Azhar, 2012). Studies have been proven that ulam has a lot of nutritional benefits and capabilities to prevent from diseases, resulting in an increased intake among people (Abas et al., 2006). However, foodborne outbreaks associated with the consumption of ready-toeat fruits and vegetables have been increasing worldwide. In Brazil, thirty fruits and vegetables related outbreaks resulted in 2926 illnesses and 347 hospitalisations from 2008 to 2014 (Elias et al., 2018).
Minimally processed fruits and vegetables are usually consumed without cooking and require no further treatment, making the presence of pathogens is a major concern. Raw vegetables can serve as vehicles for many different foodborne pathogenic microorganisms such as E. coli O157: H7, Salmonella spp., Shigella spp., Listeria monocytogenes, Campylobacter spp., Staphylococcus aureus and Clostridium botulinum (Mritunjay and Kumar, 2015). The vegetables can be contaminated from various sources such as soil, water (crop irrigation, application of pesticides and flood) and feces of animals (Ingham et al., 2005).

Faecal contamination is specifically indicating the presence of $E$. coli (Mukherjee et al., 2004). In 2006, E. coli O157: H7 contamination of lettuce and spinach resulted in 81 and 199 cases (3 deaths) in the United 
States of America (CDC 2006; FDA 2006; Sela et al., 2009; CDC, 2011). In 2008, there was an E. coli O157: $\mathrm{H} 7$ outbreak linked to lettuce resulted in 134 cases in Canada (Warriner and Namvar, 2010). Most of the cases were associated with the packaged product. Products had been washed and disinfected with hypochlorite before packaging, but the process was insufficient to eliminate E. coli $\mathrm{O} 157$ : $\mathrm{H} 7$ and leading to microbial infections to humans (Rodriguez et al., 2011). The reason behind this packaged product remained unclear, however, biofilm is believed to be the major culprit.

Biofilm is microbiologically derived sessile communities characterized by cells that are irreversibly attached to a substratum or interface to each other and embedded in a matrix of extracellular polymeric substances that they have produced. They are capable to exhibit an altered phenotype due to the effects of growth rate and gene transcription (Donlan and Costerton, 2002). Bacteria are capable to survive environmental stress, such as nutritional and oxidative stresses, desiccation, UV light exposure, and sanitizing agents with biofilms formed (Fatemi and Frank, 1999). Substrates' properties, the surface of the bacteria and genetic mechanism play an important role in biofilm formation (Shi and Zhu, 2009). According to Uhlich et al. (2006), E. coli O157: H7 can form biofilms on various types of surfaces because of its ability to attach and colonized on the surface. Biofilm can be formed by E. coli $\mathrm{O} 157$ : $\mathrm{H} 7$ not only on abiotic surfaces, but also on biotic surfaces such as spinach, lettuce, Chinese cabbage, celery, leeks, basil, and parsley (Pawar et al., 2005). Salmonella is also capable of adhering and forming biofilms on fresh produce leading to persistence and resistance to disinfection treatment, which subsequently can cause human infection (Yaron and Romling, 2014). Islam et al. (2004) reported the high persistence of nature of Salmonella enterica serovar Typhimurium in various types of vegetables such as lettuce, radish, carrot and parsley. The $S$. enterica serovar Typhimurium were persisted for more than 6 months in a compost-amended soil on which the vegetables were grown because the biofilm reached maturation stage.

The term 'rdar' (red, dry and rough) morphotype comes from distinctive colony appearance which is formed by the bacteria from the family Enterobacteriaceae on agar supplemented with Congo red dye. The occurrence of the rdar morphotype is vital for the survival of pathogenic bacteria outside of the host organism, and it is comparable with the process of spore formation in Gram-positive bacteria (Milanov, Prunic, Velhner, Pajic et al., 2015). This morphotype could play a role in the transmission of bacteria between hosts, and it is also significant for the pathogenesis of specific infection. The rdar morphotype can express curli fimbriae and cellulose as the extracellular matrix components. The expression of curli fimbriae is performed by two divergently operons $c s g$ DEFG and csgABC (Bokranz et al., 2005). Curli fimbriae are mostly made up of $\operatorname{csg} \mathrm{A}$, and it consists of a $\beta$ helix of five repeat units. Curli fimbriae are essential for host cell adhesion, biofilm formation and important stimulants of the host inflammatory response (Dueholm et al., 2011).

This work examined the ability of E. coli and Salmonella spp. to form a biofilm, rdar morphotypes and the role of csgA gene of E. coli and Salmonella spp. in stress resistance.

\section{Material and methods}

\subsection{Preparation of samples}

Each ulam sample taken from sampling site was put separately to avoid cross-contamination, kept in the polystyrene box containing ice packs and transported to the laboratory immediately. No additional washing steps were applied to the samples after collection as this would represent the actual microflora present in the ulam samples. Samples were stored at $4-8^{\circ} \mathrm{C}$ and were processed within $2 \mathrm{hrs}$ of collection. A total of $25 \mathrm{~g}$ of each cut of ulam (Figure 1) was weighed into a sterile stomacher bag. Then, the $225 \mathrm{~mL}$ of sterile buffered peptone water (BPW) (Merck, Germany) was added and then stomached for 2 mins using a stomacher (BagMixer 400, Interscience, Singapore).

\subsection{Isolation of Escherichia coli from fresh vegetables}

Thirty samples of fresh vegetables were collected from different sampling sites in Kuala Terengganu during June-August 2016. The sampling sites included supermarkets, wet markets and mini markets/groceries. The isolation of $E$. coli was done by following the method described in the Bacteriological Analytical Manual (Jackson et al., 2001). E. coli ATCC 25922 was used as a positive control.

\subsection{Isolation of Salmonella spp. from fresh vegetables}

Twelve samples of fresh vegetables were collected from different sampling sites in Kuala Terengganu during May 2017-February 2018. The sampling sites included supermarkets and wet markets. The isolation of Salmonella spp was done by referring to the method based on BS EN 12824 (Roberts and Greenwood, 2003). Salmonella ATCC 14028 was used as a positive control.

\subsection{Gram Staining}

The standard protocol of Gram staining was done by 


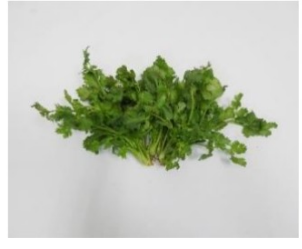

Daun Ketumbar (Coriandrum sativum

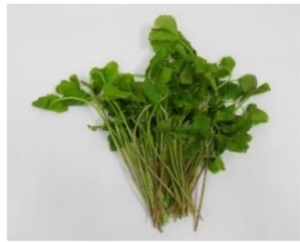

Pegaga (Centella asiatica)

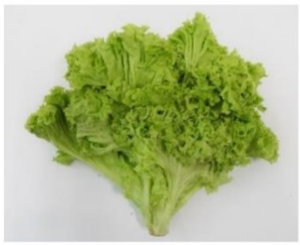

Salad Kampung (Lactuca sativa)

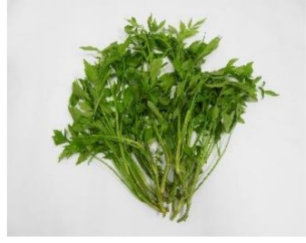

Selom (Oenanthe javanica)

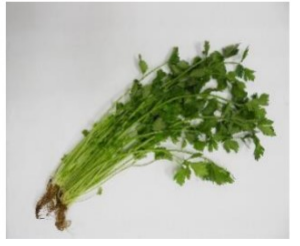

Daun Sup (Petroselinum crispum)

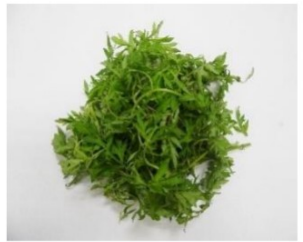

Ulam Raja (Cosmos caudatus)

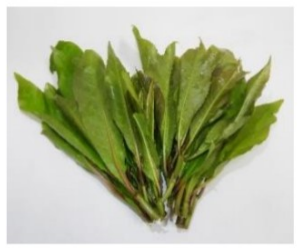

Pucuk Putat (Barringtonia racemosa)

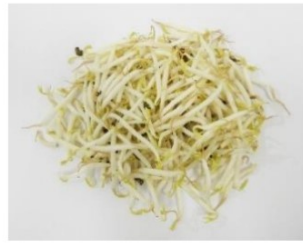

Taugeh (Vigna radiata)

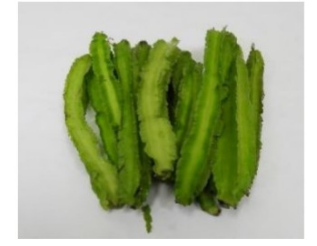

Kacang Botol (Psophocarpus tetragonolobus)

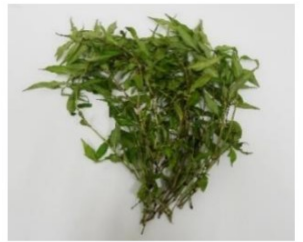

Kesum (Persicaria odorata)

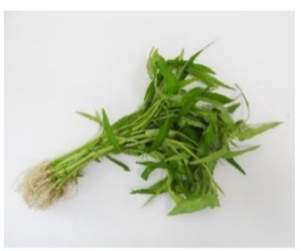

Kangkung

(Ipomoea aquatica)

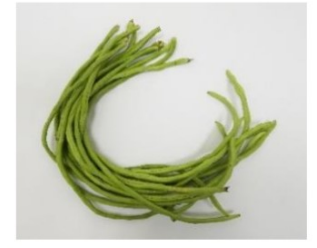

Kacang Panjang

(Vigna unguiculata)

Figure 1. The Malaysian Traditional Vegetables (Ulam)

referring to the method described by James and Natalie (2014). The results of staining were observed under oil immersion using a light microscope with a total magnification of 1000x (Leica DME, Matrix Optics (M) Sdn Bhd, Malaysia).

\subsection{Colony morphology}

Colony morphology on Congo red-supplemented agar was used to detect the formation of fimbriae in colonies. LB agar without $\mathrm{NaCl}$ consists of $10 \mathrm{~g} / \mathrm{L}$ tryptone (Merck, Germany), $6 \mathrm{~g} / \mathrm{L}$ technical agar (Oxoid, $\mathrm{UK}$ ), and $5 \mathrm{~g} / \mathrm{L}$ of yeast extract (HiMedia Laboratories Pvt. Ltd, India) was supplemented with $0.04 \mathrm{~g} / \mathrm{L}$ Congo red (Sigma Aldrich Inc., Germany). Then, $1 \mu \mathrm{L}$ of the overnight culture was inoculated into congo red agar and incubated at $25^{\circ} \mathrm{C}$ for 5 days (Abdullah et al., 2017). Their colony morphologies were observed at day 3 and 5. The morphotypes observed were red, dry and rough (rdar) and smooth and white morphotype (saw). Rdar morphotypes able to form multicellular communities and their colonies were dark red colour, with a rough surface and undulated margins. While saw morphotypes showed white colonies and expression of matrix component was absent.

\subsection{Biofilm formation protocol}

\subsubsection{Qualitative method}

Biofilm formation on glass was tested as follows: 10 $\mathrm{ml}$ Luria Bertani (LB) broth without salt contained $10 \mathrm{~g} /$ $\mathrm{L}$ tryptone (Merck, Germany) and $5 \mathrm{~g} / \mathrm{L}$ yeast extract (HiMedia Laboratories Pvt. Ltd, India) was prepared in $25 \mathrm{~mL}$ Universal bottle. Then, one loopful of the overnight culture was inoculated into the broth and incubated at $25^{\circ} \mathrm{C}$ for 4 days. Pellicle formation was recorded before and after staining with $0.1 \%(\mathrm{w} / \mathrm{v})$ aqueous crystal violet solution (Merck, Germany).

\subsubsection{Quantitative method}

The following quantitative method was used to test biofilm formation on a microtiter plate (O'Toole and Kolter, 1998): a culture of strain was grown overnight in a rich medium of Luria Bertani (LB) broth consist of 10 $\mathrm{g} / \mathrm{L}$ tryptone (Merck, Germany), $10 \mathrm{~g} / \mathrm{L}$ sodium chloride $(\mathrm{NaCl})$ (Merck, Germany) and $5 \mathrm{~g} / \mathrm{L}$ yeast extract 
(HiMedia Laboratories Pvt. Ltd, India). The overnight culture was diluted 1:100 (1\%) into fresh medium for biofilm assays. Biofilm assays medium for the strain is LB broth without salt. Then, $200 \mu \mathrm{L}$ of the dilution were added per well in 96 micro-well plates (flat bottom), typically used 6 replicate wells for each different strain. LB broth without salt (bacteria-free medium) was put together as a control. The 96 flat-bottom microplates were incubated at the $25^{\circ} \mathrm{C}$ in the Humidity Chamber Model HCP (Memmert, Germany) and at static condition for 4 days.

After 4 days, the liquid cultures were discarded, and the plates that previously used for biofilm formation were washed twice with $225 \mu \mathrm{L}$ of distilled water to discard the broth. Plates were inverted on a paper towel to remove excess moisture. Plates were then allowed to air dry in laminar flow (AVC-4DI, Esco, US) for 30 mins. Biofilm formation of different strains of $E$. coli and Salmonella spp. were stained using $0.1 \%$ aqueous crystal violet. Then, $200 \mu \mathrm{L}$ of $0.1 \%$ aqueous crystal violet was added per well and left for 20 mins. Stains were discarded and plates were rewashed twice with 225 $\mu \mathrm{L}$ of distilled water. Plates were then submerged in a bath of distilled water twice, and water has been replaced between washes. Plates were tapped on a paper towel to remove excess moisture and were allowed to air dry under the laminar flow for 30 mins. The adherent stained biofilms were dissolved with $200 \mu \mathrm{L}$ of $95 \%$ ethanol (R $\&$ M Chemicals, UK). The optical density was measured at $620 \mathrm{~nm}$ (OD $620 \mathrm{~nm}$ ) in a microplate reader (Multiskan $^{\text {TM }}$ GO Microplate Spectrophotometer, Thermo Fisher Scientific, US). The higher the absorbance, a stronger biofilm was formed.

2.7 The sequence of csgA gene for detection of curli fimbria gene (biofilm)

\subsubsection{Polymerase chain reaction}

The $\operatorname{csg} \mathrm{A}$ gene (Forward primer 5'ACTCTGACTTGACTATTACC -3' and reverse primer 5'- AGATGCAGTCTGGTCAAC -3') were used for the amplification of the DNA fragment. The csgA primers were synthesized by Integrated DNA Technologies (IDT). PCR reaction mixture, which comprised of 12.5 $\mu \mathrm{L}$ of $2 \mathrm{x}$ PCR Buffer, $5 \mu \mathrm{L}$ of dNTP mix, $2 \mathrm{mM}$ each, 1 $\mu \mathrm{L}$ of forward primer, $1 \mu \mathrm{L}$ of reverse primer, $1 \mu \mathrm{L}$ of DNA template, $0.5 \mu \mathrm{L}$ Thermostable DNA polymerase $(1 \mathrm{U} / \mu \mathrm{L})$ and $4 \mu \mathrm{L}$ of Nucleus free water to make up the reaction volume of $25 \mu \mathrm{L}$. All PCR mixture was purchased from Promega (USA), and PCR amplifications were performed in an MJ Mini Personal Thermal Cycler (Bio-Rad Laboratories, US). The cycling conditions after gradient PCR were optimized with an initial denaturation at $94^{\circ} \mathrm{C}$ for 2 mins, followed by 30 cycles of denaturation at $98^{\circ} \mathrm{C}$ for $10 \mathrm{~s}$, annealing at $54.5^{\circ} \mathrm{C}$ for $1 \mathrm{~min}$, and extension at $68^{\circ} \mathrm{C}$ for $30 \mathrm{~s}$.

\subsubsection{Gel electrophoresis}

Aliquots of $1 \mu \mathrm{L}$ PCR products were run on $1.7 \%$ TAE agarose gel (Hydragene, USA) at $100 \mathrm{~V}, 60$ minutes. The size of the amplified product was confirmed by comparison with a standard DNA marker (100 bp ladder) (Promega, USA). The presence of amplicon at $198 \mathrm{bp}$ were found positive for curli structural gene $\operatorname{csg} \mathrm{A}$. The sequencing process was sent to Apical Scientific Sdn. Bhd., Seri Kembangan, Selangor, Malaysia.

\section{Results and discussion}

In this study, we investigated in particular 23 isolates of presumptive E. coli and 6 isolates of Salmonella spp. for their ability to form biofilm and to produce the extracellular structures essential for adhesion to solid surfaces through colony morphology test. The graphical abstract is exhibited in Figure 2.

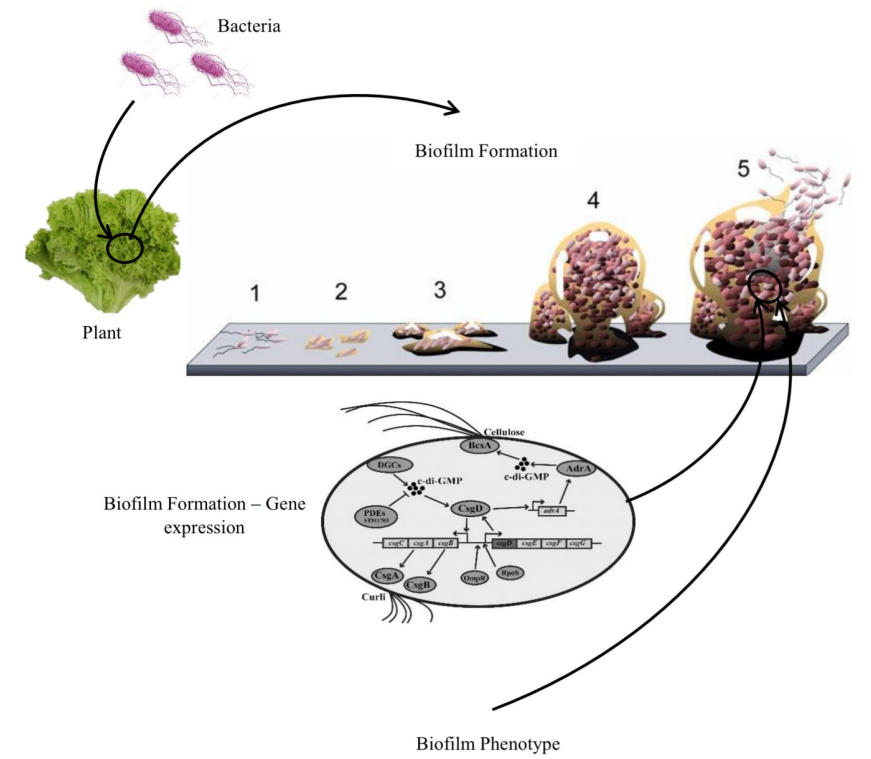

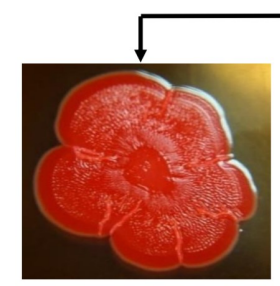

Rdar morphotype

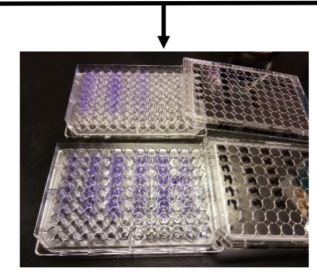

Quantitative Biofilm

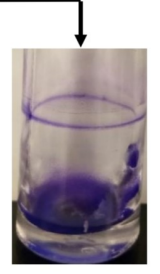

Qualitative Biofilm
Figure 2. Graphical abstract of biofilm formation on plant surface (Gantcharova et al., 2010; Unosson, 2015).

\subsection{Colony morphology test}

The colony morphology test was performed for the screening of biofilm formation. This test is fast and easy to implement among the phenotypic methods, its specificity, sensitivity, and accuracy are low compared to other quantitative and qualitative biofilm methods. Phenotypic production by all the isolates was analyzed 
and interpreted according to standard colour variation from white to red. In this study, three distinctive colony morphologies were observed red, dry and rough (rdar), intermediate and smooth and white (saw) morphotypes. Red colonies represented biofilm formers, while white represented non-biofilm formers. The colonies formed by the intermediate morphotype was not as visually distinctive in morphotype as either rdar morphotypes or saw morphotypes. The observation was carried out after $120 \mathrm{hrs}$ of incubation, as recommended by Abdullah et al. (2017). After $120 \mathrm{hrs}$ incubation at $25^{\circ} \mathrm{C}$ on Luria Bertani (LB) agar without $\mathrm{NaCl}$ supplemented with congo red, three distinctly different morphotypes were observed in the colonies formed by the E. coli strains isolated from vegetables; 78.3\% (18/23) expressed red, dry and rough (rdar) morphotypes, 13\% (3/23) intermediate morphotypes and $8.7 \%(2 / 23)$ smooth and white (saw) morphotypes. The assessment of colony morphology by Salmonella spp. showed that 100\% (6/6) showed intermediate morphotypes after inoculated on congo red agar plates presented in Table 1.

Table 1. Prevalence of Congo Red morphotypes of Escherichia coli and Salmonella spp.

\begin{tabular}{cccc}
\hline \multirow{2}{*}{ Isolate } & \multicolumn{3}{c}{ Morphotypes Prevalence } \\
\cline { 2 - 4 } & rdar & intermediate & saw \\
\hline E. coli & \multirow{2}{*}{$18 / 23(78.3 \%)$} & $3 / 23(13 \%)$ & $2 / 23(8.7 \%)$ \\
Salmonella spp. & $6 / 6(100 \%)$ & \\
\hline
\end{tabular}

Congo red supplemented agar used to visualize curli and cellulose production in the colonies. Rdar colonies isolate producing both curli fimbriae and cellulose as an extracellular matrix component. Table 2 and 3 show rdar morphotype was expressed by $18(78.3 \%)$ isolates of $E$. coli (SMDS2, SMDS4, WMDS, SMKG1, SMKG2, SMKG3, SMKG4, SMKB2, SMKB4, SMKB5, SMKB8, SMK2, SMK3, SMU2, SMT4, WMSK4, WMSK7 and WMPP2) and rdar morphotypes absent in all Salmonella enterica. Verma et al. (2018) reported that rdar morphotype characterized by both expressions of curli fimbriae and cellulose production was identified in 28 isolates (38.3\%) of $E$. coli isolated from fresh vegetables and fruits samples.

The binding of the dye congo red to E. coli and Salmonella spp. have been reported to correlate with their production of curli and cellulose. Curli are thin aggregative surface fibers which are involved in adhesion of E. coli and Salmonella to its contact host (Gophna et al., 2002). Curli fibers bind the congo red dye and specific host matrix proteins including fibronectin, laminin, plasminogen, and major histocompatibility complex class I molecules to initiate adherence and colonization in the host (Olsen et al., 1998; Gophna et al., 2001). Cellulose is an exopolysaccharide in which individual glucose monomers connected by a 1-4- $\beta$-glycosidic bond, which in bacteria is synthesized and excreted by a membraneinserted cellulose synthase complex consisting of two subunits, BcsA and BcsB (Morgan et al., 2013; Whitney and Howell, 2013). As a second matrix-component Salmonella and E. coli strains secrete cellulose as an extracellular component for mechanical and chemical protection (Zogaj et al., 2001). Previous studies have shown that curli and cellulose also play a role in E. coli attachment to plant surfaces as well. Jeter and Matthysse (2005) reported that E. coli $\mathrm{K} 12$ isolates carrying a plasmid encoding a gene for curli biosynthesis manifest a stronger attachment to tomato, Arabidopsis seedlings and alfalfa sprouts compared to those not producing curli.

While three isolates of E. coli (SMP1, SMKB3 and WMSK6) and six isolates of Salmonella spp. (WMS.HE.TT.2, SMKP.XLD.4, SMT.XLD.1, SMT.XLD.2, SMT.XLD.3 and SMT.XLD.RVS.1) expressed intermediate morphotype. The attempt had been done to prolong incubation to see whether intermediate morphotype can change to rdar morphotype; however, no changes were observed. Instead of clear rdar or saw morphotypes, these strains expressed some red binding but at levels substantially less than rdar morphotypes. The presence of red in these colonies often was higher in some regions of the colony growth, as observed by the ring of red on SMKB3/EC, WMSK6/EC and SMT1/S.

When no matrix components are expressed, the phenotypes are smooth and white (saw). It was consistent with the absence of curli on the cell surface. Saw morphotype was observed in two isolates $(8.7 \%)$ of E. coli (SMDS1 and WMSK1). In another study, a higher percentage of saw morphotype was observed. It was found that 9 isolates $(12.3 \%)$ of E. coli isolated from fresh vegetables and fruits sample did not bind with congo red dye and declared as negative (Verma et al., 2018).

\subsection{Quantitative biofilm}

Several studies have shown that E. coli and Salmonella spp. are capable of adhering and forming biofilms on multiple surfaces including metal, rubber surfaces and glass (Hood and Zottola, 1997; Joseph et al., 2001; Stepanovic et al., 2004). The assessment of biofilm formation of E. coli and Salmonella spp. In this study showed that most of them were able to form biofilms. In this study, quantitative biofilm was assessed using 96-microtitre plate. The bacteria isolates were able to form biofilm on microtiter plate heighten its ability to form biofilm on different surfaces. The microtitre plate has the advantage of being simple and can be easily modified to growth conditions and examined multiple 
Table 2. Gram stain, colony morphology and biofilm formation on the air-liquid interface of Escherichia coli

\begin{tabular}{|c|c|c|c|c|c|}
\hline Source & $\begin{array}{l}\text { Laboratory } \\
\text { Designation }\end{array}$ & Gram Stain & Colony Morphology ${ }^{a}$ & $\begin{array}{c}\text { Thin Aggregative } \\
\text { Fimbriae } \\
\text { Biosynthesis }\end{array}$ & $\begin{array}{l}\text { Pellicle on air-liquid } \\
\text { interface }^{\mathrm{b}}\end{array}$ \\
\hline Pegaga & SMP1 & Negative & intermediate & - & + \\
\hline \multirow{5}{*}{ Daun Sup } & SMDS1 & Negative & Saw & - & - \\
\hline & SMDS2 & Negative & rdar, convoluted & ++ & +++ \\
\hline & SMDS4 & Negative & rdar, convoluted & + & ++ \\
\hline & WMDS & Negative & rdar, convoluted & ++ & +++ \\
\hline & SMKG1 & Negative & rdar, convoluted & ++ & +++ \\
\hline \multirow{5}{*}{ Kangkung } & SMKG2 & Negative & rdar, convoluted & ++ & +++ \\
\hline & SMKG3 & Negative & rdar, convoluted & ++ & +++ \\
\hline & SMKG4 & Negative & rdar, convoluted & ++ & +++ \\
\hline & SMKB2 & Negative & rdar, convoluted & ++ & +++ \\
\hline & SMKB3 & Negative & intermediate & - & + \\
\hline \multirow[t]{3}{*}{ Ketumbar } & SMKB4 & Negative & rdar, convoluted & ++ & +++ \\
\hline & SMKB5 & Negative & rdar, convoluted & ++ & +++ \\
\hline & SMKB8 & Negative & rdar, convoluted & ++ & +++ \\
\hline \multirow{2}{*}{ Kesum } & SMK2 & Negative & rdar, convoluted & ++ & +++ \\
\hline & SMK3 & Negative & rdar, convoluted & ++ & +++ \\
\hline Ulam Raja & SMU2 & Negative & rdar, convoluted & ++ & +++ \\
\hline Taugeh & SMT4 & Negative & rdar, convoluted & ++ & +++ \\
\hline \multirow{4}{*}{ Salad Kampung } & WMSK1 & Negative & Saw & - & - \\
\hline & WMSK4 & Negative & rdar, convoluted & ++ & +++ \\
\hline & WMSK6 & Negative & intermediate & - & + \\
\hline & WMSK 7 & Negative & rdar, convoluted & + & ++ \\
\hline Pucuk Putat & WMPP2 & Negative & rdar, convoluted & ++ & +++ \\
\hline
\end{tabular}

Table 3. Gram stain, colony morphology and biofilm formation on the air-liquid interface of Salmonella spp.

\begin{tabular}{|c|c|c|c|c|c|}
\hline Source & $\begin{array}{l}\text { Laboratory } \\
\text { Designation }\end{array}$ & Gram Stain & Colony Morphology & $\begin{array}{l}\text { Thin Aggregative } \\
\text { fimbriae biosynthesis }\end{array}$ & $\begin{array}{l}\text { Pellicle on air-liquid } \\
\text { interface }^{\mathrm{b}}\end{array}$ \\
\hline Selom & WMS.HE.TT.2 & Negative & Intermediate & - & +++ \\
\hline Kacang Panjang & SMKP.XLD.4 & Negative & Intermediate & - & +++ \\
\hline \multirow{4}{*}{ Taugeh } & SMT.XLD.1 & Negative & Intermediate & - & + \\
\hline & SMT.XLD.2 & Negative & Intermediate & - & +++ \\
\hline & SMT.XLD.3 & Negative & Intermediate & - & ++ \\
\hline & SMT.XLD.RVS.1 & Negative & Intermediate & - & +++ \\
\hline
\end{tabular}

${ }^{a}$ Morphotypes on Congo Red agar (rdar) red, dry and rough, intermediate and (saw) smooth and white; ${ }^{b}$ Phenotype on air-liquid interface: (-) the complete absence of pellicle - lack of ability to produce biofilm; $(+)$ formation of very thin pellicle - weak biofilm producer; $(++)$ formation of thin pellicle - moderate biofilm producer, $(+++)$ formation of strong and thick pellicle strong biofilm producer.

strains in each experiment. The microtiter plate method for detection of biofilm production demonstrated that a lower percentage of isolates as strong biofilm producer compared to colony morphology test results, indicating the specificity of the method.

The isolates of E. coli and Salmonella spp. varied in their ability to produce biofilm on the surface of a microtiter plate with optical density measured at $620 \mathrm{~nm}$ ranging from $0.051-0.955 ; 0.123-0.418$ respectively. The values for optical density (OD) of E. coli and Salmonella spp. isolates are represented in Figures 3 and 4. After incubation in LB broth without salt at $25^{\circ} \mathrm{C}, 16(69.6 \%)$ $E$. coli isolates were categorized as strong biofilm producers, $2(8.7 \%)$ as moderate biofilm producers, 3 $(13 \%)$ as weak biofilm producers, whereas $2(8.7 \%)$ as negative biofilm producers (did not produce biofilm). While 4 (66.7\%) Salmonella spp. isolates were identified as strong biofilm producers, $1(16.7 \%)$ as moderate biofilm producers and $1(16.7 \%)$ as negative biofilm producers (Tables 4 and 5).

Table 6 shows the significant moderate correlation in biofilm formation of $E$. coli strains with the same morphotypes $(\mathrm{r}=0.718, \mathrm{p}<0.001)$. Results of the correlation indicate that rdar morphotypes are associated with higher biofilm formation. All rdar and intermediate E. coli and Salmonella spp. isolates were identified as 


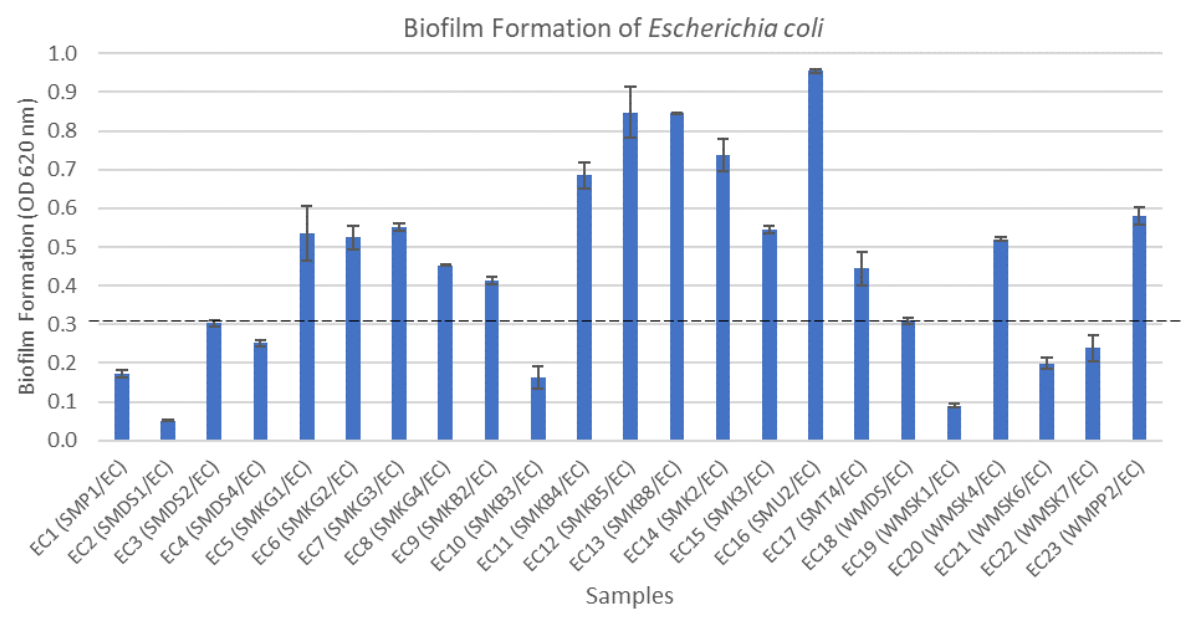

Figure 3. The Biofilm Formation of E. coli strains. The Biofilm formation was calculated by using formula; Biofilm Formation $(\mathrm{BF}) \mathrm{BF}=\mathrm{AB}-\mathrm{CW}$; $\mathrm{AB}$, stained attached bacteria; $\mathrm{CW}$, stained control wells.

*Value more than 0.30 indicate strong biofilm.

Table 4. Screening of biofilm formers of Escherichia coli

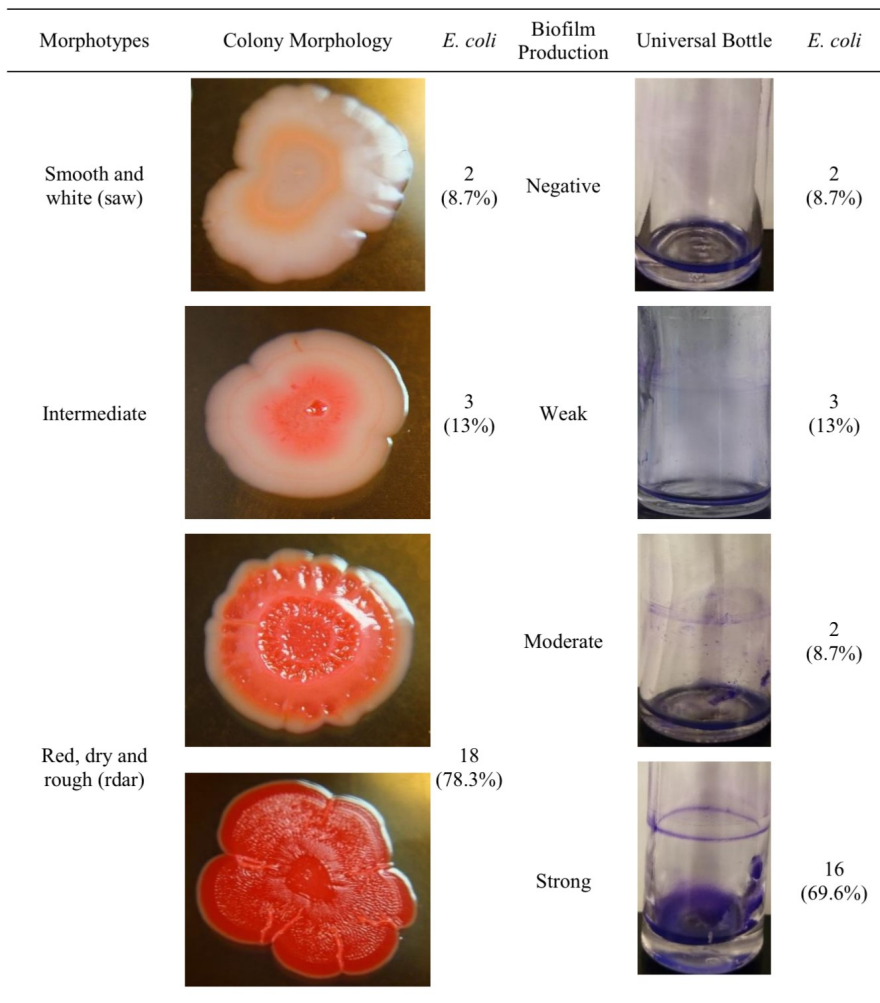

Table 5. Screening of biofilm formers of Salmonella spp.

\begin{tabular}{|c|c|c|c|c|c|}
\hline Morphotypes & Colony Morphology & $\begin{array}{c}\text { Salmonella } \\
\text { spp. }\end{array}$ & $\begin{array}{c}\text { Biofilm } \\
\text { Production }\end{array}$ & Universal Bottle & $\begin{array}{c}\text { Salmonella } \\
\text { spp. }\end{array}$ \\
\hline & & & Weak & & $1(16.7 \%)$ \\
\hline \multirow[t]{2}{*}{ Intermediate } & & $6(100 \%)$ & Moderate & & $1(16.7 \%)$ \\
\hline & & & Strong & & $4(66.6 \%)$ \\
\hline
\end{tabular}

Biofilm Formation of Salmonella spp.

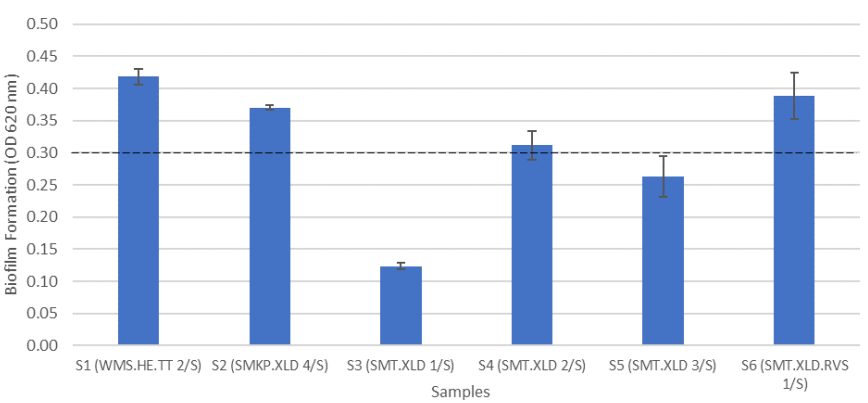

Figure 4. The Biofilm Formation of Salmonella spp. strains. The Biofilm formation was calculated by using formula; Biofilm Formation $(\mathrm{BF}) \mathrm{BF}=\mathrm{AB}-\mathrm{CW}$; $\mathrm{AB}$, stained attached bacteria; $\mathrm{CW}$, stained control wells.

*Value more than 0.30 indicate strong biofilm.

biofilm producers. Majority of the E. coli strains (69.6\%) were identified as strong biofilm producer and also able to express rdar morphotypes. While $2(8.7 \%)$ E. coli isolates were recognized as saw morphotypes and did not produce biofilm. The current results were in accordance to previous authors that described the correlation between a phenotypic appearance on congo red agar and biofilm formation (Bokranz et al., 2005; Milanov, Prunic, Velhner, Todorovic et al., 2015; Amrutha et al.,2017). Bokranz et al. (2005) demonstrated that E. coli strains expressing rdar morphotype showed a higher capacity to form biofilms than saw strains.

\subsection{Qualitative biofilm}

Table 2 and 3 present the result for biofilm phenotype at the air-liquid interface i.e., ability to form a pellicle at the air-liquid interface at $25^{\circ} \mathrm{C}$ after 120 hours incubation in LB broth without salt. A visible purple film lining the walls and bottom of the universal tubes indicated the positive result for biofilm formation. The amount of biofilm formed was categorized as weak, moderate and strong, depending on the intensity of the 
Table 6. Correlation between colony morphotypes and biofilm production of $E$. coli

\begin{tabular}{|c|c|c|c|c|}
\hline & & & Colony Morphotypes & Biofilm Formation \\
\hline \multirow{6}{*}{ Spearman's rho } & \multirow{3}{*}{ Colony Morphotypes } & Correlation Coefficient & 1 & $.718^{* *}$ \\
\hline & & Sig. (2-tailed) & . & 0 \\
\hline & & $\mathrm{N}$ & 69 & 69 \\
\hline & \multirow{3}{*}{ Biofilm Formation } & Correlation Coefficient & $.718^{* *}$ & 1 \\
\hline & & Sig. (2-tailed) & 0 & . \\
\hline & & $\mathrm{N}$ & 69 & 69 \\
\hline
\end{tabular}

visible film. The formation of a strong and thick pellicle $(+++)$ was observed in $16(69.6 \%)$ E. coli isolates (SMDS2, WMDS, SMKG1, SMKG2, SMKG3, SMKG4, SMKB2, SMKB4, SMKB5, SMKB8, SMK2, SMK3, SMU2, SMT4, WMSK4, WMPP2) and 4 (66.7\%) Salmonella spp. isolates (WMS.HE.TT.2, SMKP.XLD.4, SMT.XLD.2, SMT.XLD.RVS.1). Amrutha et al. (2017) reported $22.8 \%$ E. coli and $22.2 \%$ Salmonella isolated from fresh fruits and vegetables were strong biofilm former. Those isolates also formed a strong and thick pellicle on the test tube.

In 2 of E. coli isolates (SMDS4, WMSK7) and 1 of Salmonella spp. isolate (SMT.XLD.3) the formation of a moderate or thin pellicle $(++)$ was observed. 3 of E. coli isolates (SMP1, SMKB3, WMSK6) and 1 of Salmonella spp. (SMT.XLD.1) formed a weak or very thin pellicle $(+)$. While, 2 isolates of E. coli (SMDS1, WMSK1) did not form a pellicle at the air-liquid interface (Table 4 and 5 ). These findings were consistent with those observed in the microtiter plate.

\section{$3.4 \operatorname{csg} \mathrm{A}$ gene for detection of curli fimbria gene (biofilm)}

The $\operatorname{csg} \mathrm{A}$ gene is essential for the expression of the major subunit protein of the fibre ( $\operatorname{csg} \mathrm{A}$ subunit protein) and encoding curli fimbriae. Previous studies have shown that curli produced by E. coli O157: $\mathrm{H} 7$ and $S$. enterica play a significant role in the attachment to plant surfaces (Jeter and Matthysse, 2005). Fink et al. (2012) reported that the $\operatorname{csg} \mathrm{A}$ mutant in E. coli $\mathrm{K} 12$ and $\mathrm{O} 157$ : $\mathrm{H} 7$ was weakened in their ability to attach and colonize on lettuce leaves. A series of primer was designed by Maurer et al. (1998) to recognize the curli structural gene $\operatorname{csg} \mathrm{A}$. The expected size of the PCR product for $\operatorname{csg} \mathrm{A}$ is 200 bp (Figure 5).

One isolate from E. coli (SMK2/EC) and Salmonella (WMS.HE.TT.2/S) was selected to detect the presence of the curli selected gene. These isolates are among the highest reading of optical density (OD) when tested with the microtiter plate. CsgA gene was present in E. coli isolate (SMK2/EC) but not detected in Salmonella isolate (Figure 5). This result is consistent with those results from colony morphology test as E. coli isolate showed the obvious formation of curli fimbriae. Salmonella isolate (WMS.HE.TT.2/S) was categorized

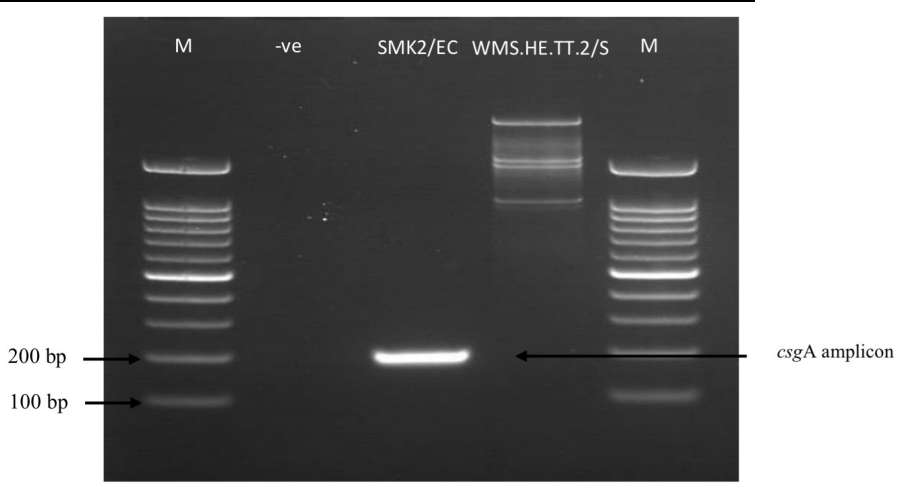

Figure 5. Representative agarose gel analysis of PCR assay targeting csgA gene in Escherichia coli (EC) and Salmonella spp. (S) isolates. Lane 1 and 5: 100 bp DNA ladder, Lane 2: Negative control, Lane 3: Sample 14/EC, Lane 4: Sample 1/S.

as strong biofilm producer, but during the colony morphology test, the formation of curli fimbriae was absent. This result was confirmed with the lack of the csgA gene (WMS.HE.TT.2/S).

Even though this isolate (WMS.HE.TT.2/S) lack of the $\operatorname{csg} \mathrm{A}$ gene, but its biofilm-forming potential is not because of this particular gene. This happens due to the other genes may be involved in the biofilm formation, which is not taken into account in this study. As biofilm is highly organized and complex structure, several genes related to biofilm formation such as $\operatorname{csg} \mathrm{D}$ (master regulator for biofilm formation), fliC (Flagella), fim $\mathrm{H}$ (Type 1 fimbriae), bcsA (cellulose) and many more (Niba et al., 2007; Schiebel et al., 2017). For example, the $\operatorname{csg} \mathrm{D}$ is a transcriptional protein that activates the biosynthesis and expression of both curli and cellulose. CsgD activates transcription of the csgBAC operon, which encodes curli structural subunits, and transcription of $a d r \mathrm{~A}$ gene, involved in cellulose biosynthesis (Brombacher et al., 2006; MacKenzie et al., 2017).

\section{Conclusion}

The present study has investigated biofilm forming potential of E. coli and Salmonella spp. isolated from fresh vegetables. The findings demonstrated that the microorganism that associated with fresh vegetables are capable of biofilm formation. The E. coli (SMK2/EC) isolates from Kesum sample was one of the highest reading of optical density (OD). Besides, the presence of the $\operatorname{csg} \mathrm{A}$ gene in the E. coli isolate (SMK2/EC) was consistent with the formation of curli fimbriae. This 
isolate represents a public health concern because it can survive and distribute through the food chain to reach the consumer causing the food contamination and disease outbreak. The use of sanitizers (sodium hypochlorite, aqueous chlorine dioxide, hydrogen peroxide) is widely used in the food industry and effective for eradicating these biofilms on plant surfaces. However, the overuse of sanitizers may be one of the driving force concerning the emergence of antibiotic-resistant in bacteria. Therefore, a better understanding of bacterial attachment to fresh produce is necessary for the development of alternative washing treatments to control E. coli and Salmonella spp. contamination during handling and processing of food products. Besides, a regular and hygienic handling practice of fresh vegetables along the supply chain is important for public health concern and maintaining the standard of food safety.

\section{Acknowledgment}

This research was financially supported by University Malaysia Terengganu through TPM Grant Mechanism (Vot No: TPM-68006/2016/84 and Food Safety and Quality Programme (Specific Study on Food Health 2016) by Ministry of Health Malaysia.

\section{References}

Abas, F., Lajis, N. H., Israf, D.A., Khozirah, S. and Kalsom, Y.U. (2006). Antioxidant and nitric oxide inhibition activities of selected Malay traditional vegetables. Food Chemistry, 95(4), 566-573. https:// doi.org/10.1016/j.foodchem.2005.01.034

Abdullah, W.Z.W., Mackey, B.M. and Karatzas, K.A.G. (2017). High phenotypic variability among representative strains of common Salmonella enterica serovars with possible implications for food safety. Journal of Food Protection, 81(1), 93-104. https://doi.org/10.4315/0362-028X.JFP-17-190

Amrutha, B., Sundar, K. and Shetty, P.H. (2017). Study on E. coli and Salmonella biofilms from fresh fruits and vegetables. Journal of Food Science and Technology, 54(5), 1091-1097. https:// doi.org/10.1007/s13197-017-2555-2

Bokranz, W., Wang, X., Tschape, H. and Romling, U. (2005). Expression of cellulose and curli fimbriae by Escherichia coli isolated from the gastrointestinal tract. Journal of Medical Microbiology, 54(12), 1171 -1182. https://doi.org/10.1099/jmm.0.46064-0

Brombacher, E., Baratto, A., Dorel, C. and Landini, P. (2006). Gene expression regulation by the curli activator $C s g$ D protein: modulation of cellulose biosynthesis and control of negative determinants for microbial adhesion. Journal of Bacteriology, 188(6),
2027-2037. https://doi.org/10.1128/JB.188.6.20272037.2006

CDC. (Centers for Disease Control and Prevention) (2006). Nutrition for everyone: Polyunsaturated fats and monounsaturated fats. Retrieved from CDC website.

CDC. (Centers for Disease Control and Prevention) (2011). Estimates of Foodborne Illness in the United States. Retrieved February, 15, 2012 from CDC website: https://www.cdc.gov/foodborneburden/2011 -foodborne-estimates.html

Donlan, R.M. and Costerton, J.W. (2002). Biofilms: survival mechanisms of clinically relevant microorganisms. Clinical Microbiology Reviews, 15 (2), 167-193. https://doi.org/10.1128/CMR.15.2.167193.2002

Dueholm, M.S., Nielsen, S.B., Hein, K.L., Nissen, P., Chapman, M., Christiansen, G. and Otzen, D.E. (2011). Fibrillation of the major curli subunit CsgA under a wide range of conditions implies a robust design of aggregation. Biochemistry, 50(39), 82818290. https://doi.org/10.1021/bi200967c

Elias, S.O., Decol, L.T. and Tondo, E.C. (2018). Foodborne outbreaks in Brazil associated with fruits and vegetables: 2008 through 2014. Food Quality and Safety, 2(4), 173-181. https://doi.org/10.1093/ fqsafe/fyy 022

Fatemi, P. and Frank, J.F. (1999). Inactivation of Listeria monocytogenes/Pseudomonas biofilms by peracid sanitizers. Journal of Food Protection, 62(7), 761765. https://doi.org/10.4315/0362-028X-62.7.761

FDA (Food and Drug Administration) (2006). Spinach and $E$. coli outbreak. Retrieved from FDA website: http://www.fda.gov/oc/opacom/hottopics/spinach.htl.

Fink, R.C., Black, E.P., Hou, Z., Sugawara, M., Sadowsky, M.J. and Diez-Gonzalez, F. (2012). Transcriptional responses of Escherichia coli K-12 and O157: H7 associated with lettuce leaves. Applied Environmental Microbiology, 78(6), 1752-1764. https://doi.org/10.1128/AEM.07454-11

Gophna, U., Barlev, M., Seijffers, R., Oelschlager, T.A., Hacker, J. and Ron, E.Z. (2001). Curli fibers mediate internalization of Escherichia coli by eukaryotic cells. Infection and Immunity, 69(4), 2659-2665. https://doi.org/10.1128/IAI.69.4.2659-2665.2001

Gophna, U., Oelschlaeger, T.A., Hacker, J. and Ron, E.Z. (2002). Role of fibronectin in curli-mediated internalization. FEMS Microbiology Letters, 212(1), 55-58. https://doi.org/10.1111/j.15746968.2002.tb11244.x

Grantcharova, N., Peters, V., Monteiro, C., Zakikhany, K. and Romling, U. (2010). Bistable expression of 
$\operatorname{csg} \mathrm{D}$ in biofilm development of Salmonella enterica serovar Typhimurium. Journal of Bacteriology, 19 (2), 456-466. https://doi.org/10.1128/JB.01826-08

Hood, S.K. and Zottola, E.A. (1997). Adherence to stainless steel by foodborne microorganisms during growth in model food systems. International Journal of Food Microbiology, 37(2-3), 145-153. https:// doi.org/10.1016/S0168-1605(97)00071-8

Ingham, S.C., Fanslau, M.A., Engel, R.A., Breuer, J.R., Breuer, J.E., Wright, T.H. and Zhu, J. (2005). Evaluation of fertilization-to-planting and fertilization-to-harvest intervals for safe use of noncomposted bovine manure in Wisconsin vegetable production. Journal of Food Protection, 68(6), 11341142. https://doi.org/10.4315/0362-028X-68.6.1134

Islam, M., Doyle, M.P., Phatak, S.C., Millner, P. and Jiang, X. (2004). Persistence of enterohemorrhagic Escherichia coli O157: H7 in soil and on leaf lettuce and parsley grown in fields treated with contaminated manure composts or irrigation water. Journal of Food Protection, 67(7), 13651370. https://doi.org/10.4315/0362-028X-67.7.1365

Jackson, G.J., Merker, R.I. and Bandler, R.B. (2001). Bacteriological Analytical Manual. Center for Food Safety and Applied Nutrition, 25(1), 180.

Jeter, C. and Matthysse, A.G. (2005). Characterization of the binding of diarrheagenic strains of $E$. coli to plant surfaces and the role of curli in the interaction of the bacteria with alfalfa sprouts. Molecular PlantMicrobe Interactions, 18(11), 1235-1242. https:// doi.org/10.1094/MPMI-18-1235

Joseph, B., Otta, S.K., Karunasagar, I. and Karunasagar, I. (2001). Biofilm formation by Salmonella spp. on food contact surfaces and their sensitivity to sanitizers. International Journal of Food Microbiology, 64(3), 367-372. https:// doi.org/10.1016/S0168-1605(00)00466-9

MacKenzie, K.D., Palmer, M.B., Köster, W.L. and White, A.P. (2017). Examining the link between biofilm formation and the ability of pathogenic Salmonella strains to colonize multiple host species. Frontiers in Veterinary Science, 4, 138. https://doi.org/10.3389/fvets.2017.00138

Maurer, J.J., Brown, T.P., Steffens, W.L. and Thayer, S.G. (1998). The occurrence of ambient temperatureregulated adhesins, curli, and the temperaturesensitive hemagglutinin tsh among avian Escherichia coli. Avian Diseases, 42(1), 106-118. https:// doi.org/10.2307/1592582

Mritunjay, S.K. and Kumar, V. (2015). Fresh farm produce as a source of pathogens: a review. Research Journal of Environmental
Toxicology, 9(2), 59-70. https://doi.org/10.3923/ rjet.2015.59.70

Mukherjee, A., Speh, D., Dyck, E. and Diez-Gonzalez, F. (2004). Preharvest evaluation of coliforms, Escherichia coli, Salmonella, and Escherichia coli O157: H7 in organic and conventional produce grown by Minnesota farmers. Journal of Food Protection, 67(5), 894-900. https:// doi.org/10.4315/0362-028X-67.5.894

Milanov, D.S., Prunic, B.Z., Velhner, M.J., Pajic, M.L. and Cabarkapa, I.S. (2015). RDAR morphotype: A resting stage of some Enterobacteriaceae. Food and Feed Research, 42(1), 43-50. https:// doi.org/10.5937/FFR1501043M

Milanov, D., Prunic, B., Velhner, M., Todorovic, D. and Polacek, V. (2015). Investigation of Biofilm Formation and Phylogenetic Typing of Escherichia coli Strains Isolated from Milk of Cows with Mastitis. Acta Veterinaria, 65(2), 202-216. https:// doi.org/10.1515/acve-2015-0017

Morgan, J.L., Strumillo, J. and Zimmer, J. (2013). Crystallographic snapshot of cellulose synthesis and membrane translocation. Nature, 493(7431), 181. https://doi.org/10.1038/nature11744

Niba, E.T.E., Naka, Y., Nagase, M., Mori, H. and Kitakawa, M. (2007). A genome-wide approach to identify the genes involved in biofilm formation in E. coli. DNA Research, 14(6), 237-246. https:// doi.org/10.1093/dnares/dsm024

Olsen, A., Wick, M.J., Morgelin, M. and Bjorck, L. (1998). Curli, fibrous surface proteins of Escherichia coli, interact with major histocompatibility complex class I molecules. Infection and Immunity, 66(3), 944 -949 .

O'Toole, G.A. and Kolter, R. (1998). Initiation of biofilm formation in Pseudomonas fluorescens WCS365 proceeds via multiple, convergent signalling pathways: a genetic analysis. Molecular Microbiology, 28(3), 449-461. https:// doi.org/10.1046/j.1365-2958.1998.00797.x

Pawar, D.M., Rossman, M.L. and Chen, J. (2005). Role of curli fimbriae in mediating the cells of enterohaemorrhagic Escherichia coli to attach to abiotic surfaces. Journal of Applied Microbiology, 99(2), 418-425. https://doi.org/10.1111/j.13652672.2005.02499.x

Reihani, S.F.S. and Azhar, M.E. (2012). Antioxidant activity and total phenolic content in aqueous extracts of selected traditional Malay salads (Ulam). International Food Research Journal, 19(4), 14391444.

Rodriguez, F.P., Campos, D., Ryser, E.T., Buchholz, 
A.L., Posada-Izquierdo, G.D., Marks, B.P. and Todd, E. (2011). A mathematical risk model for Escherichia coli O157: H7 cross-contamination of lettuce during processing. Food Microbiology, 28(4), 694-701. https://doi.org/10.1016/j.fm.2010.06.008

Sela, S., Fallik, E., Wojciech, J.F., Robert, L.S., Bernhard, B., Stanley, E.P. and Florkowski, R.L.S. (2009). Chapter 13 - Microbial quality and safety of fresh produce postharvest handling, 2nd ed., p. 351398. San Diego: Academic Press. https:// doi.org/10.1016/B978-0-12-374112-7.00013-5

Schiebel, J., Bohm, A., Nitschke, J., Burdukiewicz, M., Weinreich, J., Ali, A. and Schierack, P. (2017). Genotypic and phenotypic characteristics associated with biofilm formation by human clinical Escherichia coli isolates of different pathotypes. Applied Environmental Microbiology, 83 (24), e01660-17. https://doi.org/10.1128/AEM.01660 $-17$

Shi, X. and Zhu, X. (2009). Biofilm formation and food safety in food industries. Trends in Food Science and Technology, 20(9), 407-413. https://doi.org/10.1016/ j.tifs.2009.01.054

Stepanovic, S., Cirkovic, I., Ranin, L. and SvabicVlahovic, M. (2004). Biofilm formation by Salmonella spp. and Listeria monocytogenes on plastic surface. Letters in Applied Microbiology, 38 (5), 428-432. https://doi.org/10.1111/j.1472765X.2004.01513.x

Uhlich, G.A., Cooke, P.H. and Solomon, E.B. (2006). Analyses of the red-dry-rough phenotype of an Escherichia coli O157: H7 strain and its role in biofilm formation and resistance to antibacterial agents. Applied Environmental Microbiology, 72(4), 2564-2572. https://doi.org/10.1128/AEM.72.4.25642572.2006

Unosson, E. (2015). Antibacterial Strategies for Titanium Biomaterials. Uppsala, Sweden: University of Uppsala, PhD Thesis.

Verma, P., Saharan, V.V., Nimesh, S. and Singh, A.P. (2018). Phenotypic and virulence traits of Escherichia coli and Salmonella strains isolated from vegetables and fruits from India. Journal of Applied Microbiology, 125(1), 270-281. https:// doi.org/10.1111/jam.13754

Warriner, K. and Namvar, A. (2010). The tricks learnt by human enteric pathogens from phytopathogens to persist within the plant environment. Current Opinion in Biotechnology, 21(2), 131-136. https:// doi.org/10.1016/j.copbio.2010.01.004

Whitney, J. C. and Howell, P.L. (2013). Synthasedependent exopolysaccharide secretion in Gram- negative bacteria. Trends in Microbiology, 21(2), 6372. https://doi.org/10.1016/j.tim.2012.10.001

Yaron, S., and Romling, U. (2014). Biofilm formation by enteric pathogens and its role in plant colonization and persistence. Microbial Biotechnology, 7(6), 496516. https://doi.org/10.1111/1751-7915.12186

Zogaj, X., Nimtz, M., Rohde, M., Bokranz, W. and Romling, U. (2001). The multicellular morphotypes of Salmonella Typhimurium and Escherichia coli produce cellulose as the second component of the extracellular matrix. Molecular Microbiology, 39(6), 1452-1463. https://doi.org/10.1046/j.1365- 